\title{
Smart Digital for Mobile Communication Through TVUPI Streaming for Higher Education
}

\author{
https://doi.org/10.3991/ijim.v13i05.10286
}

\author{
Deni Darmawan ${ }^{\left({ }^{凶}\right)}$, Edi Suryadi, Dinn Wahyudin \\ Universitas Pendidikan Indonesia, Bandung, Indonesia \\ deni darmawan@upi.edu
}

\begin{abstract}
Television of Universitas Pendidikan Indonesia (UPI) is still in a condition of needing further development. To make improvements to tvupi products in the form of web streaming, in further research in 2017 will be conducted public test and development of Mobile Audience through Smart Digital Mobile. Some broadcast programs that are needed soon are the educational and arts education programs of local wisdom. The product of this advanced research, tvupi gained complete trust from all segments of viewers from the academic community of UPI. The content test and ease of access are expected to be able to get an overview of the information needs of campus television impressions by the wider community.
\end{abstract}

Keywords-Mobile communication, TV streaming, smart digital mobile, tvupi

\section{Introduction}

Learning products at the level of University are often unable to answer the challenge of fulfilling the instrumental of the problem-solving. Some of the backgrounds of this phenomenon are caused by less competitive conditions, only to fulfill some routine tasks, and the lack of innovation and pragmatic thoughts from lecturers, technicians, and practitioners. There are still many other factors that cause learning outcomes are not connected with the needs in the world of work. To address this matter, the scientific steps that can be done by the lecturers are through the Scientific Research Group Program (SRGP) which is the product is technology oriented. One of the SRP's programs that can be done among others in the field of TV Stream is the product of the learning communication system. From this scientific study, the results are developed for the online lecture course in Communication Education. Furthermore, through this product-oriented SRGP, it can support the effort to disseminate university information through the digital communication system to compete in national and international quality. The idea is supported by research results from who stated that: in general, the senior assistants view streaming as a school management strategy that supports good quality education in line with the school objective. (Azlin Norhaini Mansor, Prem Prethaban Maniam, Michael C. Hunt, Mohamed Yusoff Mohd Nor. 2016) 
From the description above, the research will be conducted by utilizing the results of previous research to make a renewable innovation of a research process ever undertaken in cooperation with the University of Malaysia, USM which is related to the Streaming Web for Creative Learning. From the analysis of the results of the study, there is an opportunity for broader development efforts in the context of the fulfillment and strengthening of the field of communication systems expertise for learning (Hartati, T., Darmawan, D., Mulyasari. 2013). As one of the digital product, this research will be directed to the fulfillment of the needs of the academic community is to build digital television with the support of web streaming.

Strategically, product utilization from television streaming will be utilized by UPI civitas academics through smart digital mobile television. It is also useful for improving the quality of ICT skills management in the design of the digital learning communication system in the form of digital-online television. This condition is very much in line with the findings who stating that "Empirical evidence demonstrates that two other factors, top management and peer support and competencies in using specialized ICT tools significantly influence teachers' level of ICT usage in the teaching and learning process ."(Virginian Teeroovengadum, Nabeel Heeraman and Bhavish Jugurnath University of Mauritius. 2017)

In this research, it will be produced some products that can improve the quality of web streaming television management as a learning communication system in UPI. In particular, the focus of the problem will be realized in the form of products:

- Syllabus and SAP Tools in Education Communication courses

- Evaluation of the sustainability programs of tvupi broadcast based on the web streaming

- Mobile Smart Digital Development in expanding the reach of tvupi viewers based on web streaming

In the context of academic practice, this research is aimed to answer the collaborative maturity between the scientific study of the lectures with the tasks and functions of the public relations that is intended to be able to produce web streaming tvupi supported through the development of expertise and practical knowledge in learning and news and imaging UPI imaging tasks. More practically and effectively in 2017, tvupi will be developed through Smart Digital Mobile technology.

\section{$2 \quad$ Literature Review}

\subsection{Web streaming application}

Web streaming can be defined as a special page that designed to be integrated between the online and offline operating systems, for the benefit of the presentation of some digital information. A number of definitions of web streaming are derived from the terms applied in video streaming. Due to the influence of the development 
of the broadcasting world, various breakthroughs have been developed by experts so that television broadcasting needs to be accessible to the public without having to have a complete television station. Thus, web streaming appears that is widely used to broadcast television programs globally. With this online digital capability, then in the era now finally many television stations utilizing Streaming technology. According to that streaming is a process of delivering data in a continuous and steady stream that allows users to access and use files before data is fully exposed (Darmawan, D. 2011). This opinion is in line with what was stated about the Realtime concept that is: "To implement real-time processing, a buffer is set up in the streaming server. The data in the buffer keeps actual so that the data sent to a client end for playing back is the latest,(Chen, D.L., Li, Z., Wang, Y., Zhao, L.F. and Zhang 2013). Since the video encoding format is H264 in the system, the playback operation of the video streaming is designed to start from I frame (keyframe)(Zeng, B., et al. 2008). The SPS and PPS needed for decoding are also be sent at the begging of video together with I frame. These two points must ensure to complete realtime video processing."

In developing streaming for communication purposes in broadcast or television broadcasting context, the existence of World Wide Web technology (website) or often known as www, is a much needed digital technology. Through this streaming then the television show can be repeated and replayed as needed regarding Synchronous or Asynchronous. In terms of financing, to build streaming television can be more efficient and can reach the audience will be broader and faster to be accessible with advantages on aspects

- Classify the subject matter

- A script in the form of script/scenario shooting

- Shooting

- Camera technique

- Basic Visual Effects

- Editing and product trials

- Publishing through uploading to the website

\subsection{TVUPI.edu web streaming broadcast program database}

Broadcast program management that must be done through TV Streaming is almost not much different from that managed by other professional television stations, both public and private. In managing the broadcast program, it will require a storage system of some broadcast programs either broadcast live or broadcast delay or re-broadcast. Thus, it will be required a server for storage of the program which is then on the server will need an adequate database. The function of this database will determine the amount of TV Streaming broadcasts will be broadcasted worldwide. So, in this section researchers feel it is important to review what and how this database with the aim that the support of digital storage systems in the form of this database is able to contribute sufficiently to smooth service of web streaming tvupi. 
To manage the database required a software called DBMS (Database Management System). DBMS is a software system that allows users to create, maintain, control and access databases in a practical and efficient manner. With DBMS, users will more easily control and manipulate existing data. While RDBMS or Relationship Database Management System is one type of DBMS that supports the relationship or relationship between tables. In addition to RDBMS, there are other DBMS types, such as Hierarchy DBMS, Object Oriented DBMS, etc. In terms of academic learning, the product of web streaming tvupi will be one of the centers of study of the development of communication science, especially communication education, considering tvupi with the support of this web streaming system is in LPTK institutions that have the function of creating prospective educators.

\subsection{Enterprise information system for TVUPI's web streaming}

In the process of developing an information and communication system that tends to culminate in the realization of an event program database system. Then this will require the study of designing a particular information system with the appropriate methodology type. The study related to the enterprise information system (EIS), its architecture is expected to have functions in support of the development of the website streaming system. Some experts explain as according to (Daniel, M. 2008) explains that: An enterprise architecture is a plan of record, a blueprint of the permitted structure, arrangement, configuration, functional groupings/partitioning, interfaces, data, protocols, logical functionality, integration, technology, of IT resources needed to support a corporate or organizational business function or mission.

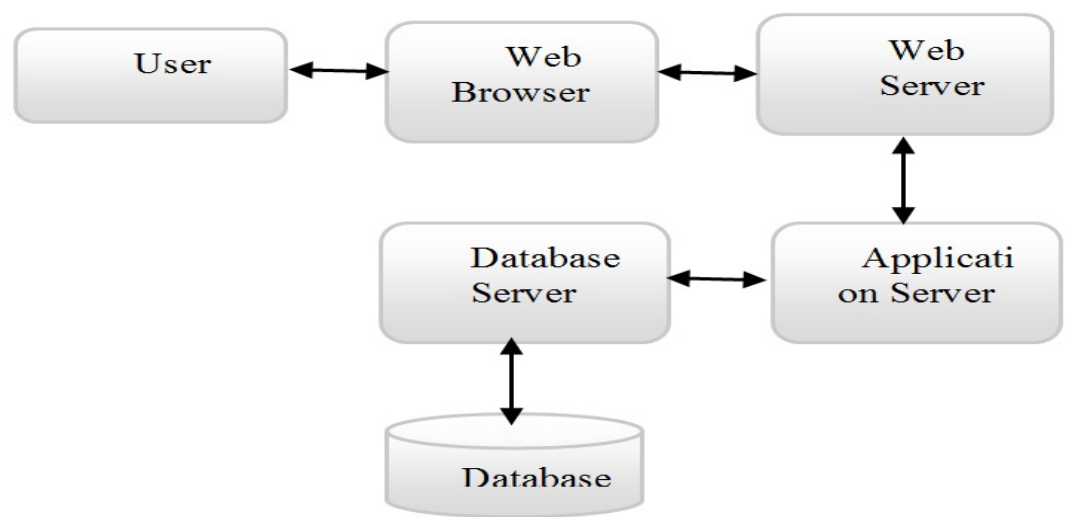

Fig. 1. EIS of tv streaming

(Source: Adaptation of EIS Lecture Materials)

From the above opinion, it is clear that EIS is very important to provide direction to programmers and data managers about the blueprint, a data structure with its relation, filter searching arrangement, content configuration, data grouping 
function to facilitate the search, as well as interface communication layer television streaming (Anna Hadiana. 2012). Figure.1 is one configuration of an EIS work system that has been adapted to the web browser in its operation.

Implementation of EIS/EA (enterprise architecture) requires the study of methodology in the system work. In order to build a database of television programs adapted to the subdirectory of the web streaming- tvupi.edu page, the development methodology used is the TOGAF method(Daniel, M., et.al 2008 .). The TOGAF method provides a context for the use of multiple architectural frameworks, models, and assets in conjunction with TOGAF ADM. Besides TOGAF as the basic architecture in developing information technology in an organization including educational organizations In this context, the UPI environment is supported by educational communication lecture activities. TOGAF consists of 8 phase in the form of cycle. In the 4th phase focused development of technology architecture. The phases in the TOGAF method can be seen in Figure .2.

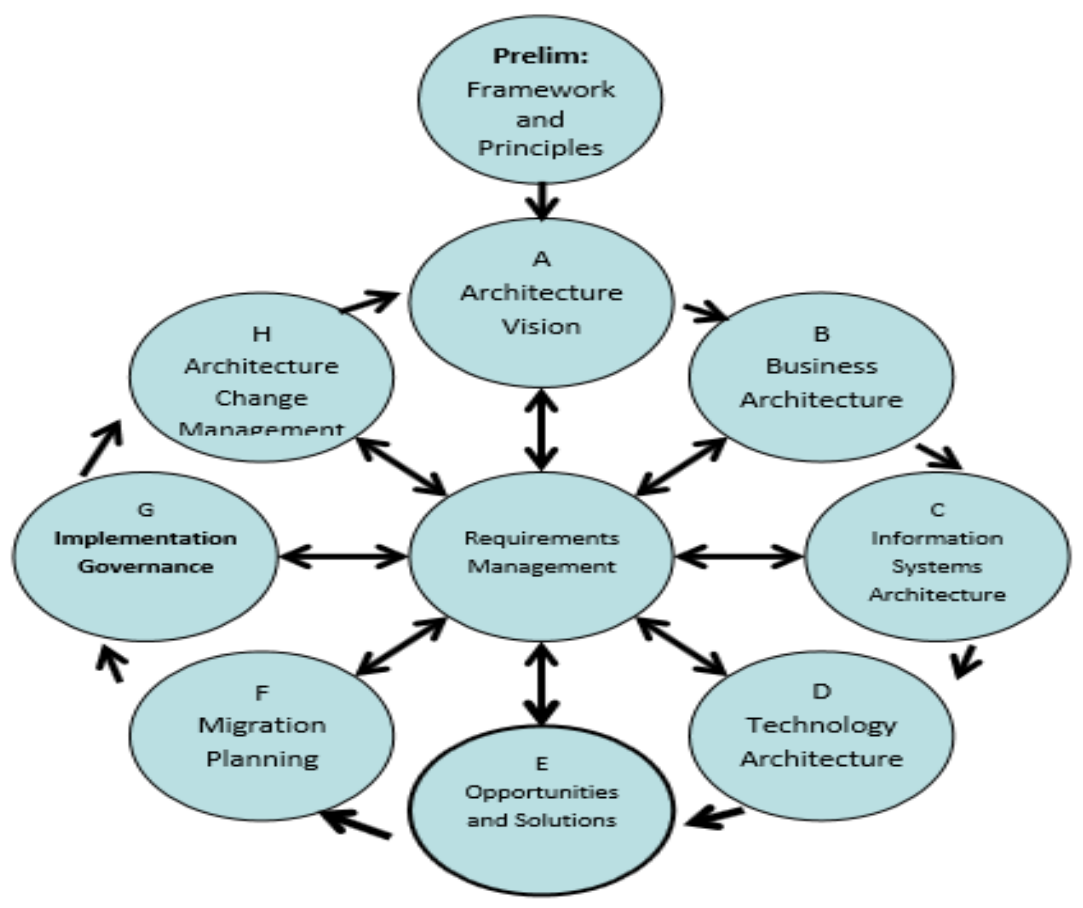

Fig. 2. Development Proses of TOGAF ADM (Lankhorst, Marc., Drunen 2008.)

Other opinions in some framework sites include that TOGAF is a framework for EA which provides a comprehensive approach to the design, planning, implementation, and governance of an enterprise information architecture. TOGAF is a registered trademark of The Open Group. TOGAF is a high level and holistic approach to design, which is typically modeled at four levels: Business, 
Application, Data, and Technology. As an open standard, TOGAF is widely adopted to support EA. The opinion confirms that the implementation methodology of the EIS with TOGAF allows it to conduct a series of development of online television information systems, complete and intact to the extent that is expected to materialize in building a tvupi web streaming program.

\subsection{The course of communication education}

This course is the subject of MKBS group of the field of study which must be taken by students of Education Technology Study Program which take Concentration of Information and Communication Technology (ICT) teachers as well as learning engineer teachers. The course is usually taken on even semesters (six) according to the UPI curriculum structure since legalized by TPK in 2015 which belongs to the field of study for the concentration of ICT teachers.

The purpose of this course is aimed at students to be able to design, develop and test various forms and types and communication models for various fields. One area of study of educational communication is the academic world and the world of broadcasting. As required by an educational institution such as UPI, the benefits of the outcome of this course is to contribute thoughts to all academic community to be able to build a special website to meet the needs of broadcasting as required by the institution of public relations owned by UPI today.

\subsection{Research methodology}

This study uses the research and development approach which adapt 10 main steps namely

- Literature study and script preparation of tvupi.edu web streaming development materials and analyzing baseline data

- Formulation of initial design of tvupi web streaming

- Development of enterprise information system database for storage of broadcast programs

- Development of integrated database information engine between broadcast delay and live broadcast

- Validation of tvupi.edu web streaming prototype with TOGAF approach

- Online trial of the database engine of broadcast tvupi.edu web streaming program on the web with individual pages

- The process of entry and update of tvupi.edu broadcast program data by classification of broadcast category filter in accordance with the database system

- Trials of ease, speed, web streaming of tvupi.edu access from various regions

- Validation and Decimation of tvupi.edu web streaming in the Presentation Form and use of shared access

- Launching web streaming tvupi.edu. to manage news information and digital television shows and public relations information to support UPI imaging 
All the steps in this R \& D research approach were adapted from (Gall, M., Damien \& Borg Wolter, R. 1992.). Furthermore, the Focus Group Discussion (FGD) Guideline was performed using two categories of approaches, ie analysis for test results data vision of design and development web streaming tvupi.edu that is adaptive to educational communication courses, where an analysis of the stages of development and trial-revision will be conducted using qualitative data analysis from (Milles and Huberman. n.d.). As for data analysis to test the impact of each test at this stage of R \& D will be done by using a simple statistical approach with a reason to find which program is widely accessed by the audience.

\section{$3 \quad$ Result}

\subsection{Syllabus and RPS course of communication education}

This research product is a learning instrument that aimed at supporting the improvement of lecture quality of Education Communication. Syllabus and RPS were developed by referring to the research-oriented stages of product lectures in and out of the classroom by students and lecturers, namely tvupi with web streaming-based program as the findings of the utilization of Technology Acceptance Model (TAM). The findings are supported by previous researchers who confirmed that the intention of an individual to make use of a particular technology has been found to be highly associated with his or her actual usage of the technology and two main determinants of usage intention as suggested by the Technology Acceptance Model (TAM), are the user's ease of use and perceived usefulness of technology (Davis, F. 1989).

Thus the learning experience provided is a real experience of building a realtime television-based television communications system. At the end of the lecture, students are given the opportunity to present their streaming products. This research-based lecture product refers to and supports the achievement of the existing competency standards in the Indonesian National Qualification Framework by utilizing ICT products in the digital age, the findings of this research reinforce the role of ICT as described by (Kreijns, K., Vermeulen, M., Kirschner, P.A., Buuren, H.V. and Acker, F.V. 2013) who stated that the use of ICT in education improves the teaching and learning process by providing support to teachers and students and connecting them to each other and a wide range of information in an efficient way.

\subsection{Sustainability evaluation of website broadcast program streaming TVUPI from academic Society of UPI}

Sustainability evaluation of broadcast tvupi website broadcasting program is done by the office of public relations office in carrying out its duties to cover and produce tvupi broadcast program, especially by request from the leadership. This 
finding proves the opinion of (Azlin Norhaini Mansor, Prem Prethaban Maniam, Michael C. Hunt, Mohamed Yusoff Mohd Nor. 2016) about streaming: Streaming refers to the act of grouping students into classes based on their intellectual and academic endeavors in this study (Macqueen, S. 2008) (Kumar, P. A. 2004.). This is still done considering the financing aspect of a broadcast program product is quite expensive thus every product broadcast program that continues to be evaluated is focused on the financing aspect of the program. Sustainability evaluation of tvupi's web streaming program is done through ADDIE (Analysis, Design, Development, Implementation, and Evaluation). Here are the results of the analysis using this ADDIE approach:

Analysis: Aimed at assessing aspects of preparedness infrastructure suggestions, and supporting digital systems for a live streaming tvupi program production process. This kind of readiness is primarily concerned with the availability and compatibility of production equipment. As has been done by many research teams as well as tvupi.edu crew until now constrained in the results of the analysis of readiness and availability of infrastructure aspects. The results of the research analysis indicate that the availability of building facilities, or adequate room is needed as a tvupi production service. Based on these conditions for tvupi sustainability, among others, will migrate on Smart TV Digital, as explained by (Wang, Z.H., et al. 2014) stated that in Smart TV broadcasting, service providers charge subscribing fee by scrambling the program with a CAS (Conditional Access System) as well as controlling the illegal reception of the charged program according to (Rohrer, F., Feleke, N., Zhang, Y.T., Nimley, K., Chitkushev, L. and Zlateva, T. 2016). Digital TV CAS has a history for nearly 30 years. Most of the CA adopts the smart card way to decrypt and at the same time carries out the binding of machine and card(Chen, D.L., Li, Z., Wang, Y., Zhao, L.F. and Zhang 2013). CAS protects not only on live TV but also on VoD, data broadcast TV, TV value-added services such as mail wallet, etc. The results of the analysis of tvupi development with reference to streaming technology support can be seen in the following table.1.

Table 1. The Result of Analysis Smart Digital Technology for Streaming TVUPI

\begin{tabular}{|c|l|c|c|}
\hline No & $\begin{array}{c}\text { Audiences Classifica- } \\
\text { tion }\end{array}$ & $\begin{array}{c}\text { Smart Digital Technology } \\
\text { Mobile Offline }\end{array}$ & $\begin{array}{c}\text { Smart Digital Technology } \\
\text { Mobile Online }\end{array}$ \\
\hline 1 & Leaders & 223 & 5662 \\
\hline 2 & Lecturer & 674 & 1297 \\
\hline 3 & Academic Profesional & 167 & 234 \\
\hline 4 & Academic Staf & 246 & 342 \\
\hline 5 & Student & 25451 & 36209 \\
\hline
\end{tabular}

Design: This assessment is addressed to the aspect of the program content assessment and program broadcast time in which the results indicate that the storage needs of the broadcast program database have also been designed with a time limit system. This means that broadcast tvupi web streaming can only be viewed in the live version that is at the time of activity and added with the announcement of airing period. It also still stores a number of database system needs in the form of the 
server (computer server) to be independently managed by a team of researchers who are also media and publications in UPI public relations office. During this time to support the delayed and uploaded lie broadcast on the YouTube server is more likely to be used by tvupi. This condition is reinforced by the opinion of (Jane de Almeida, Maria Amelia Eliseo, Cicero Inacio da Silva, Helena Prates, Vic Von Poser, Brett Stalbaum, Nilton Gomes Furtado. 2016), who stated that The most widely used platform for streaming, it allows the edition of the broadcasted material after the end of the streaming. However, YouTube does not allow consecutive edition of the broadcast content, and you cannot insert audio, cut or alter any content consecutively to the streaming.

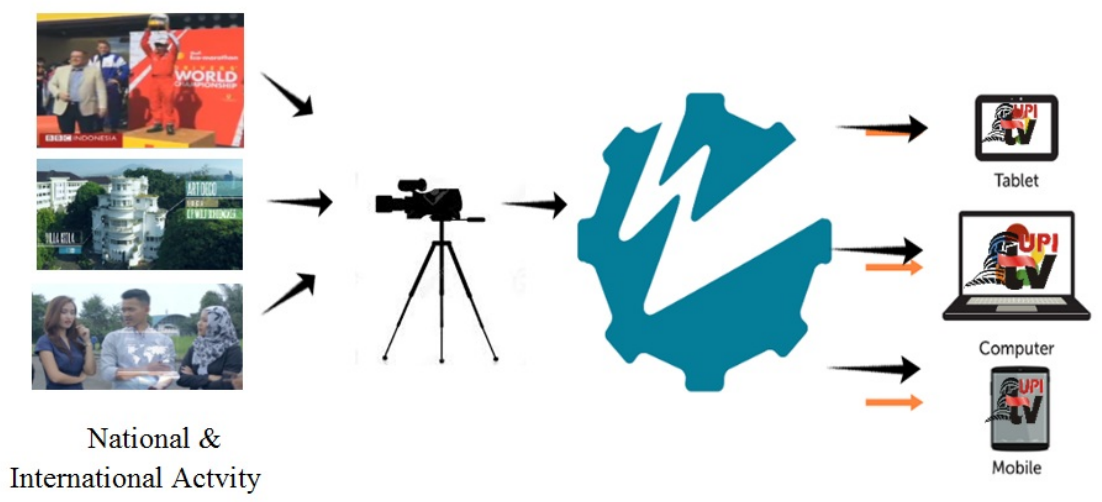

Fig. 3. Web streaming tvupi Through Wowza Streaming Engin with browser-based Encoder and Player (no plugins required)

Develop: This aspect is intended to evaluate the sustainability of the 4 aspects of development that is

- SOP for live stream product type tvupi broadcast program

- SOPs for the number and competence of human resources, which until now still introduce public relations staffs assisted by outsourcing experts and contributor public relations staff

- Eevaluation of live streaming and broadcast programs that capable of supporting the findings of new models and methods in learning

- The broadcasting time, from field findings, indicates that the broadcast hour for a live streaming TV streaming program must be adjusted to watching time or audience occasions, especially the academic community in getting watch time or by chance to access tvupi streaming

Thus the time of broadcast hour should be adjusted with the rest hours of the lecturers, teachers, and students, within 12 hours a day. Mapping of the hour can be 4 hours in the morning, 4 hours in the afternoon and 4 hours of the night. Segment time is what allows adaptive and a lot of opportunities watched by viewers who not only by the academic community UPI but by the wider community, especially the 
teachers and learners. As the server support from YouTube to serve reruns is also very well prepared. Especially for learning purposes for UPI students, the presence of YouTube is very important. Some researchers,(Maslawati, Mohamad, Izyan Safwani Ismail, Normilah Wahab 2016) affirm that the use of YouTube in the classroom as teaching the material to prompt speaking is an effective way of making learning more meaningful (Maslawati, Mohamad, Izyan Safwani Ismail, Normilah Wahab 2016). Using YouTube can prompt students to present differing viewpoints, express thoughts and feelings healthily, and practice critical thinking. The use of YouTube videos also has the potential to increase skill building for a variety of learners, including this generation of students, who expect to encounter technology in the classroom(Cooper, J. R. M., Walker, J., Marks, J., \& McNair 2011).

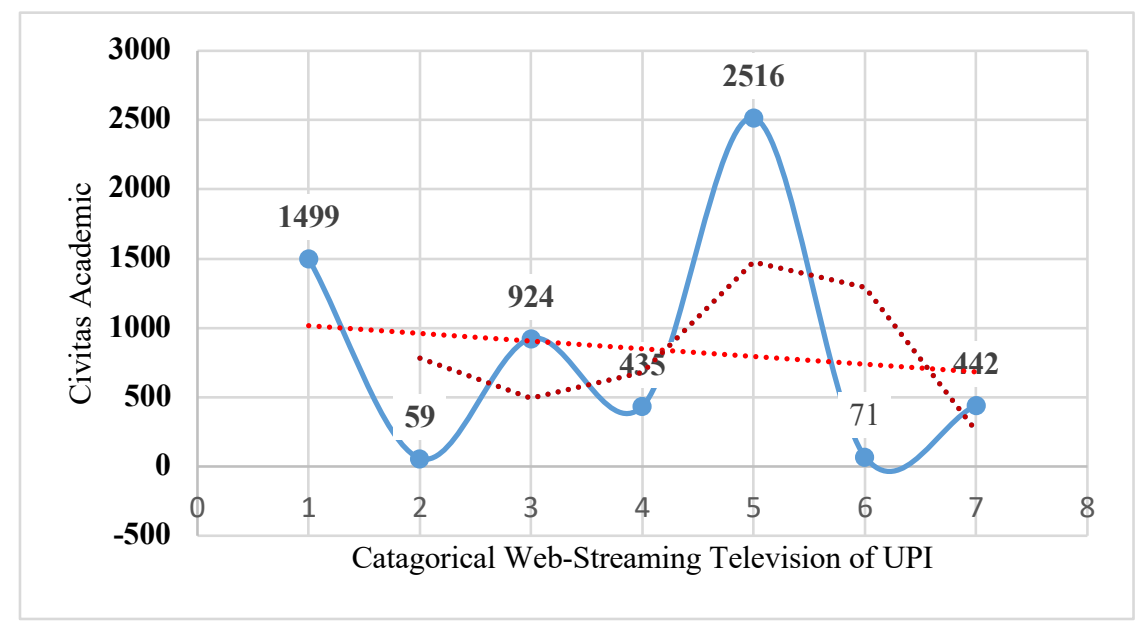

Fig. 4. Analysis Result of the Two Phases from Development of the tvupi Streaming Broadcast Categories

In the picture above the results of the analysis of tvupi streaming development efforts carried out through 2 assessment phases turned out to show a stable trend above the lowest score of -500 from the total number of UPI academics. The results of the positive trend for the first phase obtained the highest vote of 1000 people, for the positive trend of the second phase assessment of 1500 people. The highest category trend is the live streaming category no. 2, which is about The Scientific Discussion, only 57 people, and the highest is scientific visiting which reaches 2516 people from the UPI academic community.

Implementation: This stage is aimed at the evaluation process for all tvupi broadcast television shows and broadcast programs. During the study lasted about two years then the implementation of the tvupi program run in accordance with the design that has been planned. Nevertheless, there are still many shortcomings, especially facilities and infrastructure owned now. Ideally during this tvupi program implemented by optimizing hardware, software and brain ware that exists. 
Especially for the programs classified into tvupi's flagship program in its implementation is still done by the university public relations office supported by the contributor of a number of related study programs, such as education and communication technology.

Various schedule and program plan production and tvupi broadcast impressions during this well run and able to meet the needs of information and communication messages for all UPI academic community and also outside communities both nationally and internationally. To realize the implementation target of tvupi webstreaming products, the following is one of the tvupi live streaming shows by using youtube about coverage of robot contest activities among students throughout Indonesia, as shown in figure 5 below.

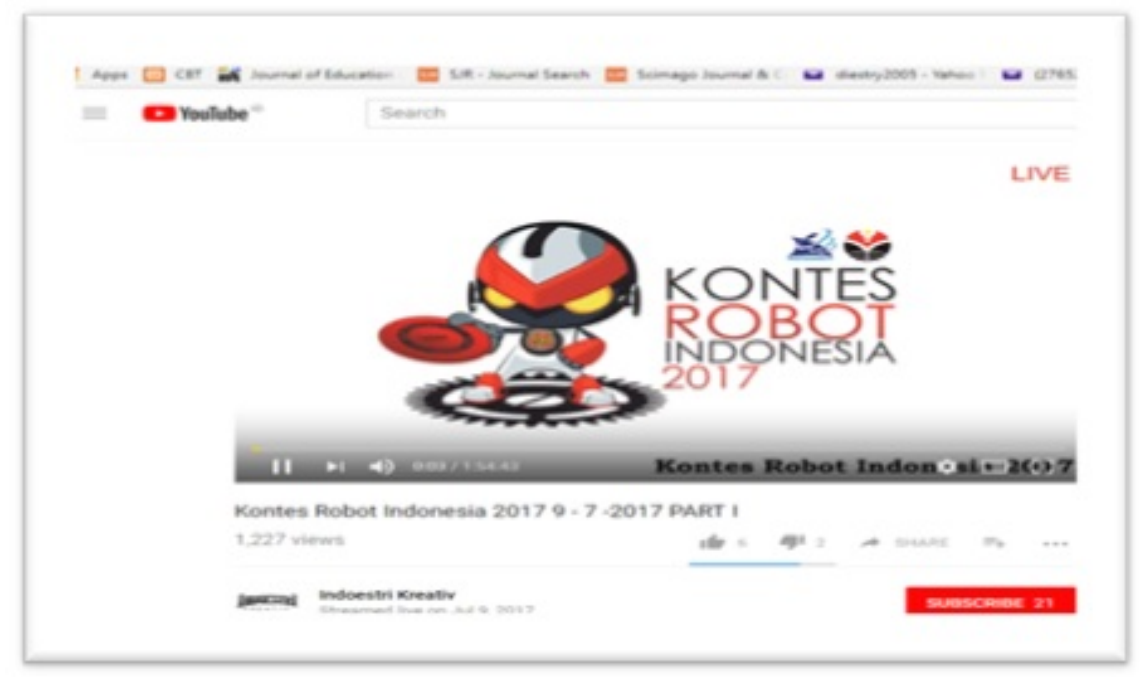

Fig. 5. Viewed an Example of the Development tvupi Program Television Based on Web Streaming through the youtube database system

Evaluation: This stage is aimed at assessing the classification of tvupi broadcast programs viewed asynchronously, from the evaluation results can be seen the findings of data as follows. 


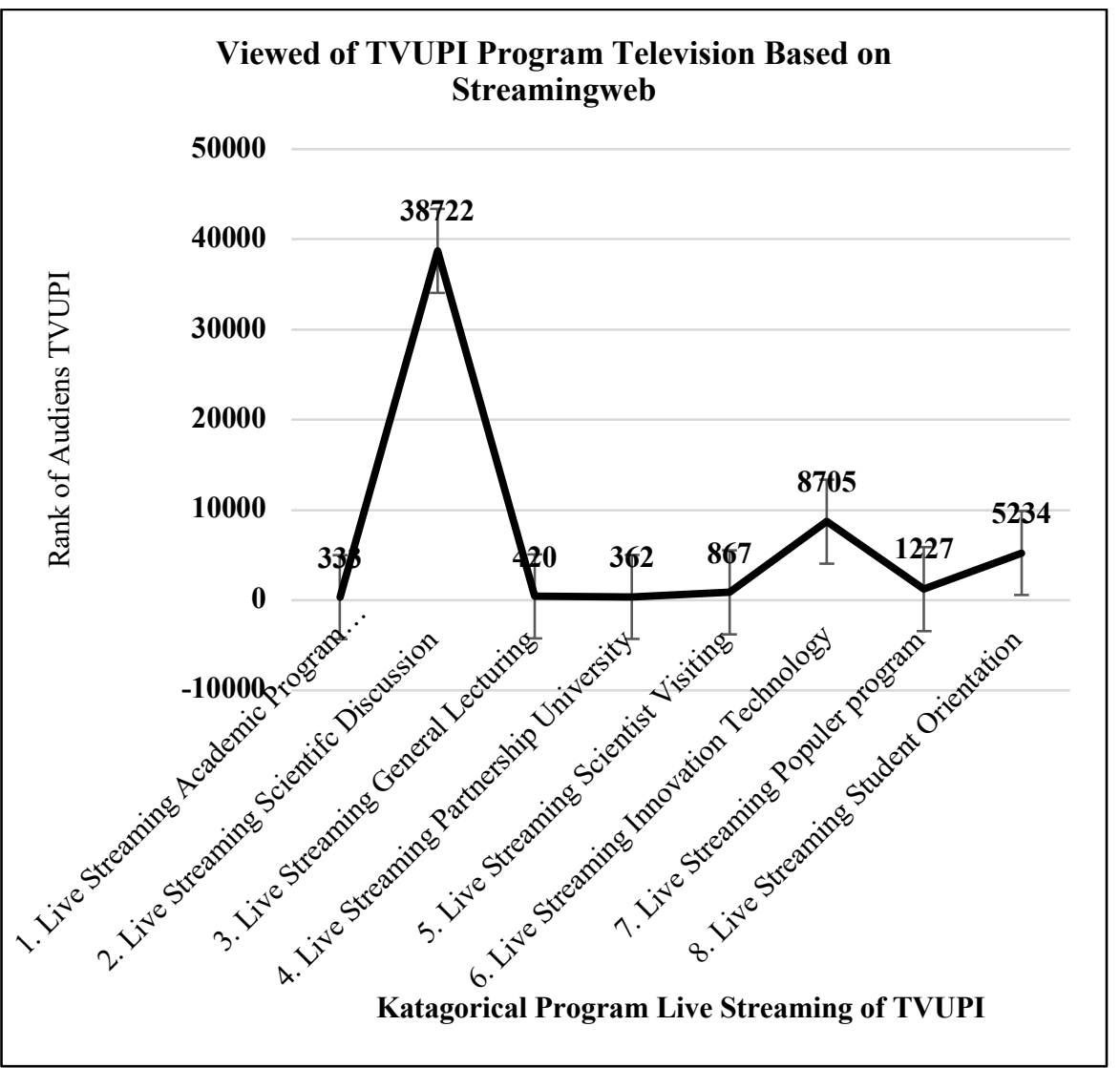

Fig. 6. Data Viewed of TVUPI Program Television Based on Web Streaming

From the research data shown in Figure.6 shows the number of viewers who for

- Year was watching tvupi live streaming program with the number of 8 segments of the event shown. Apparently, the highest is the live streaming program number

- The Scientific Discussion, that has reached 38,722 people

- Then, the audience of the live streaming number 6, about Innovation Technology, as many as 8,705

- Other live streaming broadcast program reaches just under 1000 people

This condition needs to be improved in terms of an interesting communication message on all six live streaming broadcast programs on tvupi, as in the content of the lowest graduation academic program, which only reached 333 people. This condition when viewed from the support infrastructure in terms of hardware, especially the availability of the server, it still relies on free servers YouTube, Thus 
the viewers lack the time when will see live considering the duration of live streaming is available only 1.5 hours at the time the program is broadcast.

The scores of evaluation results from the broadcast tvupi program Based on web streaming, the results can be seen in the following figure.

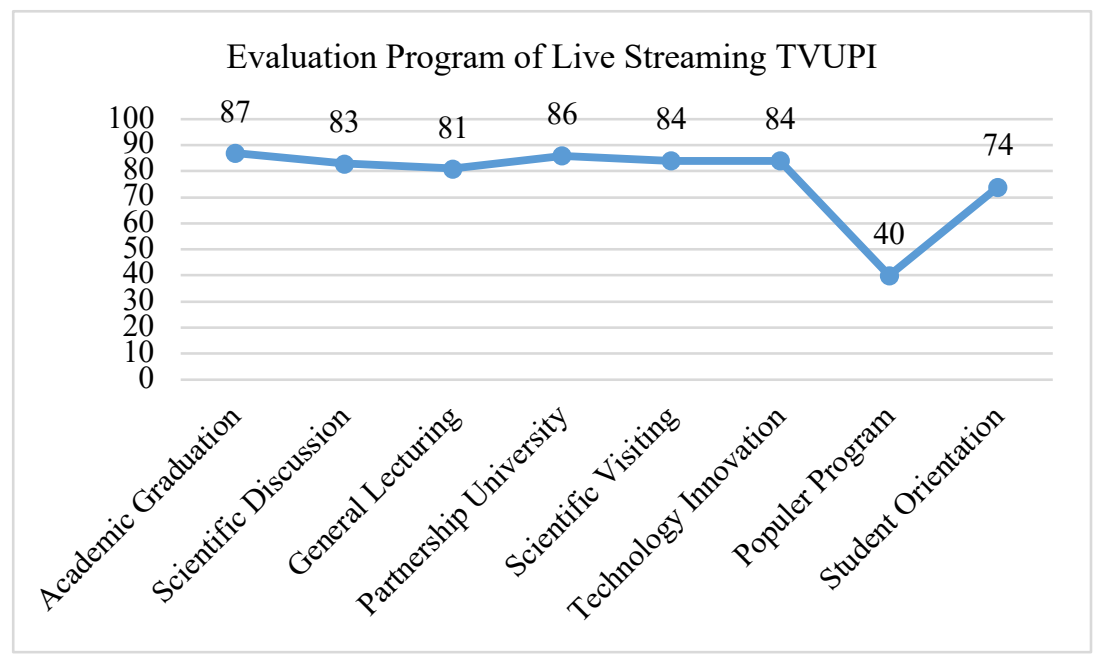

Fig. 7. Evaluation Program of Live Streaming tvupi

From Figure.7, it can be seen that the evaluation of live streaming program impressions broadcast by tvupi shows that there is an average of nearly the same program that is above the average score of 84 , especially for broadcast programs related to Academic Graduation Activity which reaches the average score 87 . Then the average for Scientific Discussion program reaches an average score of 83 , for the 81 scores general lecturing program, the broadcast program of partnership university reaches an average score of 86 , the scientific visiting program reaches an average score of 84 and the broadcast program associated with Technology Innovation reached an average score of 84 . The average score for broadcast programs that are below the average of 80 is the program broadcast program that is only reached 40 and the program broadcast student-oriented reach land-land score 74. Thus there is two tvupi broadcast program which has to be improved the quality of its contents.

\subsection{Mobile smart digital development to expand TVUPI audience reach based on web streaming}

The findings for the development of tvupi in the form of mobile smart digital in the first year have been tested, but constrained policy and financing efficiency of a tv product was not optimally done. Thus, in this second year the development of web streaming including live program there is Mobile Smart Digital model has been designed in such a way by following the partnership procedures: 
- Prototype TV Streaming We UPI Analysis

- Introduction of Mobile Smart Digital Television

- Analyze the advantages of each limitation

- Make revisions to each other's adjustments

- Mutually complement by building access from Mobile Smart Television to tvupi streaming sources.

- Socialization and Maintenance access

Utilization of Mobile smart Digital Television technology, is one variant of research utilization which has been done by(Cooper, J. R. M., Walker, J., Marks, J., \& McNair 2011) which explains that, the ever-increasing data rate in wireless network provides a good condition in video transmission, and the video-delivery technology and its applications in wideband radio network have been widely researched (Kumar, P. A. n.d.), (Li, Y.Z., et al. 2013). The cellphone live streaming system uses mobile phones to complete video data acquisition.

\section{$4 \quad$ Result and Discussion}

\subsection{Sustainability educational communication on web streaming TVUPI}

The findings indicate that the sustainability of tvupi development and utilization as an educational communication model can be studied and developed more strategically. The study and development are related to the policy of university leaders who will strategically manage how the tvupi programs grow more varied. tvupi is not only a campus community television but rather a television that has a commercial role and partnership with the communications industry. Likewise, in establishing partnerships for the provision of education and learning through television broadcasting programs, can be done through cooperation with the Center of Communication, and Communication Technologies of Education Ministry. The two studies are strongly supported by the opinion of UPI academic community and also illustrated in the lecturing process in one of the educational communication courses, where the UPI students are also able to have competence if needed by the industrial partners and the organization of television based education. If it is associated with student learning outcomes in Education Communication courses obtained during this research, then the aspect of the sustainability of tvupi web streaming can be continued its development and utilization by the students.

\subsection{Mobile television for all-academic communication at university level}

In this digital era, the role of television media that has migrated to the digital tv era can be watched through a mobile phone. This situation is predicted will affect the communication process. Similarly in the world of education, especially in college that prints prospective teachers, the existence of mobile television is very important. UPI as one of the leading universities in Indonesia, in early 2016 has 
been cooperating with Smart Digital Television company that is able to offer programs of the live broadcast of all campus activities, whether the event is held on campus or within the country, or outside the campus or outside country. Thus, the process of academic communication by the lecturers, students, and researchers will become more dynamic and widely performed. However, the challenges of infrastructure and financing needs are high enough, so that the academic communication process by using mobile media is only done by using the youtube server as the result of this research. Similarly, new mobile television media using the personal mobile phone and has not been designed to integrate with streaming web tvupi system.

\subsection{Hardware support for mobile communication}

The low number of live streaming programs found in this study indicates the weak support of mobile devices that have to be registered by the special admin of the tvupi management. This condition causes the opportunity to access a limited time live streaming broadcast that is 1.5 hours will be very difficult to do. Thus registration every mobile phone owned by UPI academic community will be done in the future. This effort is crucial in supporting the success of the mobile educational communication process when the live streaming broadcast associated with academic activities in the UPI environment increase.

\section{Conclusion}

In order to disseminate academically scientific research products, the publication process in the form of Publication Articles has been able to publish in the International Journal with the focus of tvupi web streaming study. Implementation, The continuation of tvupi streaming website broadcasting program from UPI Academic community, has been done by involving all levels of civitas academics with the results of the distribution of opinions that tend to vary in providing tvupi streaming assessment, in particular, the power system aspect, availability, and quality of the broadcast, streams developed. Utilization and support from Mobile Smart Digital in expanding the reach of tvupi audiences very rapidly where each program broadcast lives or delay, able to reach the average of $40-87 \%$ from UPI academic community.

From the results of research, discussion and conclusion formulation above then research on the tvupi -based streaming web has become a standard of education communication implementation. Support infrastructure and human resources must be balanced and able to demonstrate the mobile smart television development program in the world. In order to strengthen the findings of this research, it is necessary by the system of product publication, publication of written works, and smart digital mobile. Thus the program on the development of streaming television will take place properly and optimally. This should be supported by business strategy systems and market availability. 


\section{Acknowledg3ment}

This research is funded by the Scientific Group Research Program of the University of Indonesia Education Grant, Fiscal Year 2017, No. 4826/UN40/KM.2017.

\section{$7 \quad$ References}

[1] Anna Hadiana., 2012. 2012. "Enterprise Information System. Bandung: Program Pasca Sarjana STMIK - LIKMI Bandung.” 2012.

[2] Azlin Norhaini Mansor, Prem Prethaban Maniam, Michael C. Hunt, Mohamed Yusoff Mohd Nor., 2016. 2016. "Benefits and Disadvantages of Streaming Practices to Accommodate Students by Ability. Creative Education." 6(7): 2558. https://doi.org/10.4236/ce.2016.717241

[3] Chen, D.L., Li, Z., Wang, Y., Zhao, L.F. and Zhang, D.J. 2013. 2013. "The Main Technical Characteristics and Software Architecture of NGB SMART TV OS. Radio and Television Information, National Academy of Broadcasting Science, 2013-10.” : 2013.

[4] Cooper, J. R. M., Walker, J., Marks, J., \& McNair, M. (2011). 2011. "Using YouTube to Bridge the Gap between Baby Boomers and Millennials. Journal of Nursing Education, 50, 299-300. Http://Dx.Doi.Org/10.3928/01484834-20110419-03.” : 20110419. https://doi.org/10.3928/01484834-20110419-03

[5] Daniel, M., 2008. "Enterprise Architecture A to Z: Framework Bussiness Modeling, SOA and Infrastructure Technology. New York: CRC Press.": 2008. "Www.TogafModeling.Org.Pdf."

[6] Darmawan, D., 2011. 2011. "Video Streaming. Bandung: Diskusi Web Streaming for Creative Writing. Pelatihan Collaborative Research UPI-USM.”: 2011.

[7] Davis, F., 1989. 1989. "Perceived Usefulness, Perceived Ease of Use, and User Acceptance of Information Technology. MIS Quarterly, 13(3), p.319.” 13(3): 1989. https://doi.org/10.2307/249008

[8] Gall, M., Damien \& Borg Wolter, R., 2003. "Operation Research in Education.Pdf."

[9] Hartati, T., Darmawan, D., Mulyasari., 2013. 2013. "Video Streaming For Creative Writing At International Elementary School; Journal of Education and Learning. 3 (1), 10-25.” 3(1): 2013. https://doi.org/10.11591/edulearn.v7i1.175

[10] Jane de Almeida, Maria Amelia Eliseo, Cicero Inacio da Silva, Helena Prates, Vic Von Poser, Brett Stalbaum, Nilton Gomes Furtado., 2016. 2016. "Sensemaking: A Proposal for a Real-Time on the Fly Video Streaming Platform. International Journal of Creative Education. (7), 2515-2523." (7): 2523. https://doi.org/10.4236/ce.2016.716238

[11] Kreijns, K., Vermeulen, M., Kirschner, P.A., Buuren, H.V. and Acker, F.V., 2013. 2013. "Adopting the Integrative Model of Behaviour Prediction to Explain Teachers' Willingness to Use ICT: A Perspective for Research on Teachers' ICT Usage in Pedagogical Practices. Technology, Pedagogy, and Education, 22(1), Pp.55-71.” 22(1): 2013. https://doi.org/10.1080/1475939x.2012.754371

[12] Kumar, P. A., 2004. "Ability Grouping and Academic Achievement. Masalah Pendidikan.Pdf."

[13] Lankhorst, Marc. Drunen, Hans van (2007). "Enterprise Architecture Development and.Pdf." 
[14] Li, Y.Z., et al., 2013. 2013. "Research on Mobile Streaming Media Rate Adaptive Method Based on Wireless Network Environment. Intr Journal: Microcomputer \& Its Applications" . (32), 54-56.” (32): 2013.

[15] Macqueen, S., 2008. 2008. "Between-Class Achievement Grouping for Literacy and Numeracy: Academic Outcomes for Primary Students. In: Proceedings of AARE 2008 Conference (Pp. 1-12). Brisbane, QLD: University of Technology." : 2008.

[16] Maslawati, Mohamad, Izyan Safwani Ismail, Normilah Wahab, Saripah Mamat. 2016. 2016. "Medical Students' Challenges and Strategies in Producing Web TV Programs on YouTube. International Journal of Creative Education. (7), 604-618. DOI: 10.4236/ Ce.2016.74063." (7): 74063. https://doi.org/10.4236/ce.2016.74063

[17] Milles and Huberman., 1992. "Analysis of Data Kualitatif..Pdf."

[18] Rohrer, F., Feleke, N., Zhang, Y.T., Nimley, K., Chitkushev, L. and Zlateva, T., 2016. 2016. "Android Security Analysis and Protection in Finance and Healthcare. Boston University MET.": 2016.

[19] Virginian Teeroovengadum, Nabeel Heeraman and Bhavish Jugurnath University of Mauritius., 2017. 2017. "Examining the Antecedents of ICT Adoption in Education Using an Extended Technology Acceptance Model (TAM). International Journal of Education and Development Using Information and Communication Technology. 13 (3), 423." 13(3): 2017.

[20] Wang, Z.H., et al., 2014. 2014. "Applications of a Streaming Video Server in a Mobile Phone Live Streaming System. Journal of System Simulation. 26 5(23), 56-561." 5(23): 2014. https://doi.org/10.4236/jsea.2014.712085

[21] Zeng, B., et al., 2008. 2008. "Design and Implementation of Performance Measure Tool for Stream Media Applications Based on Active Measurement. Journal of Computer Applications. (28), 832-836." (28): 2008.

\section{Authors}

Deni Darmawan, Educational Technology Departement and Communication Science, Bandung, Indonesia. He often works as Researcher on Orbicom UNESCO member, from 2013 until now. From 2017 until now he works as Publication review for International Journal Computer Sciences (JCS), he is a Journal Manager for Edutech at UPI, JTEP on the school of postgraduate Educational technology of IPI, Gunahumas of UPI. Email deni darmawan@upi.edu

Edi Suryadi, Researcher at the University of Indonesia Education in Smart City; mobile strategy communication, and Information System integrated digital data of Indonesian education universities. Email: edi suryadi@upi.edu

Dinn Wahyudin. A researcher at the University of Indonesia Education in the field of mobile strategy communication; he works as a researcher for Digital Curriculum for Higher Education at Chung Nam University, South Korea. He is also a member of USAID Researchers. Email: dinn_wahyudin@upi.edu

Article submitted 2019-02-08. Resubmitted 2019-03-23. Final acceptance 2019-03-23. Final version published as submitted by the authors. 